\title{
Effects of Coolants on the Welding Zone of Mild Steel Rods In Corrosive Media
}

\author{
Adeyemi, G.J', Stephen, Joseph Temitope and Akindele, Ojo David \\ Mechanical Engineering Department, Ekiti State University, Ado Ekiti, Nigeria \\ 1Adeyemi4unad@yahoo.com \\ ABSTRACT
}

\begin{abstract}
The study on corrosion rate of welded mild steel rods in two corrosive media (water and cassava water) with the effect of local coolants (palm oil, coconut oil, groundnut oil, water and air) on the weldments has been studied. The results showed the trend of corrosion rates of mild steel in weldments in water and cassava water. Though, weight loss of specimens was constant in the corrosive media, this was due to the fact that weight loss increases with increase in immersion time, and corrosion rate does not follow the same trend due to concentration of stagnant ions blocking the creation of more ions and thus reducing $\mathrm{Fe}^{2+}$ activities in the media. Specimen cooled by air has the least corrosion rate in table water $(0.31 \mathrm{~mm} / \mathrm{yr})$, then cassava water $(0.46 \mathrm{~mm} / \mathrm{yr})$. Air cooling causes downtime in production and it is not recommended. The corrosion rate of specimen cooled by water is highest out of all four selected media; cassava water $(2.00 \mathrm{~mm} / \mathrm{yr})$, table water $(1.08 \mathrm{~mm} / \mathrm{yr})$, hence, water- quenching is not recommended in table water and cassava water. Groundnut oil- quenched specimen had relatively higher corrosion rate in table water $(0.92 \mathrm{~mm} / \mathrm{yr})$ and cassava water $(1.07 \mathrm{~mm} / \mathrm{yr})$; it is not recommended in table water and cassava water media. Palm oil-quenched specimen had the relatively least corrosion rate in table water and cassava water and can be recommended in water and cassava water media. Coconut oil-quenched specimen had the highest corrosion rate in table water and cassava water hence it cannot be recommended in any media.
\end{abstract}

Keywords: Coolant, Corrosive media, Corrosion rate, Mild steel, Welding zone.

\section{INTRODUCTION}

Mild steel is a type of steel alloy that contains a high amount of carbon as a major constituent. Alloys make it possible to compensate for the shortcomings of a pure metal by adding other elements. Besides carbon, there are many metal elements that are used in steel such as chromium, manganese, tungsten and vanadium (Ashby et al, 1992). All these elements along with carbon, act as hardening agent. A steel alloy with a high carbon content is mild steel, which is in fact much harder and stronger than iron. (Smith et al, 2006).

Mild steel is the cheapest and most versatile form of steel and serves every application which requires a large amount of steel. The high amount of carbon also makes mild steel vulnerable to rust. Naturally, people prefer stainless steel to mild steel, when they want a rust free technology. Mild steel is also used in construction as structural steel. It is also widely used in the car manufacturing industry (Smith et al, 2006).
Corrosion: Corrosion is the disintegration of an engineered material into its constituent atoms due to chemical reactions with its surroundings. These surroundings, such as water, salt water, mud water, air etc. are corrosive media (Baroux, 1995). Some forms of corrosion are: galvanic corrosion, crevice corrosion, intergranular corrosion, pitting and crevice corrosion etc.

Corrosive media: Metallic material constitutes a great and major part of the construction material element in industries, agricultural equipment, oil and gas and process and allied industries. In these industries, the metallic materials as a result of interaction with its environment, losses its integrity over a period of time such material cannot perform effectively (Callister, 1995).

Cassava water: Problems of corrosion are more pronounced in the processing industries, especially in agro- processing industries. The production of biodegradable industrial raw material from purely agricultural source has increased in recent times. For instance, the factory processing of cassava produces 
the toxic compound hydrogen cyanide, called the cassava water. It is very corrosive responsible for corrosion of agro-processing equipment which is usually made of plain carbon steel. The corrosiveness of the cassava water is due to the cyanide ion in the cyanogenic glycosides whose concentration varies widely as a result of environmental factors, location, and soil types (Kendrim et al, 1995). Fermentation of cassava pulp for 96hours during baked cassava powder processing reduced the hydrogen content by $50 \%$, soaking of sliced cassava for 24 hours, $40 \%$, and sun- drying, 15\% (Kendrim et al, 1995).

Water: Corrosion occurs in the presence of water, water which has a constituent of oxygen and iron reacts with oxygen to become rust. The involvement of water accounts for the fact that rusting occurs much more rapidly in moist conditions as compared with dry environments (Hollenman and Wiberg, 2001).

Welding on mild steel: Mild steel is defined as any steel that has low carbon in it and about $85 \%$ of welding is done using this type of steel. They are the steels that are most often used in construction or industrial fabrication. They are welded through the use of gas, arc or resistance welding. Mild steels are resilient and they can be bended or twisted or moved into other shapes as they are welded.

Coolant: Coolant is a type of cutting fluid and also a lubricant designed specifically for metalworking and machining processes. There are various kinds, which include oils, oil-water emulsions, pastes, gels, aerosols (mists), and air or other gases. This project is emphasizing on using air, water, palm oil, ground nut oil, coconut oil.

Aim and objective of the study: This project research work aims at evaluating the trend of corrosion rates of mild steel weldments in water storage and transport facilities and gari processing equipments. These are experimentally simulated by using table water and cassava water respectively as the corrosive media.

In a broader view to look at other previous works been researched on corrosion in relation to the objective of this project, using different corrosive media. It cannot be over emphasized that corrosion is a global concern affecting all areas of production and industries.
Corrosion behaviour of welded mild steel: Corrosion is said to be a prevailing destructive phenomenon in science and technology (Ita and Offiong, 1996), in industries, such as pulp and paper industry, power generation, underground structures, chemical and oil industries. Corrosion often causes exorbitant losses of materials, energy, and money and results in increased maintenance, unplanned shutdowns and possible serious accidents in engineering installations including offshore facilities.

The study on corrosion propensity of welded mild steel in corrosive media has been studied (Zhang and Cheng, 2009). It was said that in extreme cases, welded mild steel can develop corrosion to crack and eventually failure. Localized corrosion in form of a pit can lead to pitting and may provide sites for fatigue initiation and additionally, corrosive agents like sea water may lead to greatly enhanced growth of the fatigue crack. Pitting corrosion also occur much faster in areas where micro structural changes have occurred due to welding operations (Zhang and Cheng, 2009).

Coolants and corrosion rates: The several studies have been investigated that production work in many industries where mild steel is needed requires heavy cutting and welding over long time periods and typically produces more heat than ordinary air can remove. Rather than pausing production while the materials cools, using liquid coolant such as water, removes significantly more heat more rapidly, and can also speed cutting and reduce friction and tool wear, then quenching it in water or oil, these rapid cooling results in a hard and brittle martensitic structure (Smith Et $A l, 2006)$. It was studied that continuous growing environmental concerns are providing the impetus for increased demand and usage of vegetable oils (palm oil, coconut oil e t c) in lubricants and coolant for many applications with respect to resource renewability, biodegradability, and adequate performance in a variety of applications (Gawrilow, 2003).

Studies on some corrosive media: The cyanide contents of cassava have been identified by many investigators as the main species responsible for corrosion (Alagbe et al, 2005). Effort also has been made to study the effect of cassava fluid on corrosion performance of mild steel. The work of (Jekayinfa et al, 2005), established that mild steel materials are unsuitable for use in cassava processing without some forms of corrosion protection options with the use of inhibitors to reduce the corrosion rate. 


\section{EXPERIMENTAL PROCEDURE}

Materials and specimen procurement and preparation: The $16 \mathrm{~mm}$ diameter mild steel rod procured was prepared into a $150 \mathrm{~mm}$ length as shown in figure 1 which was cut into 20 pieces by a hack saw.

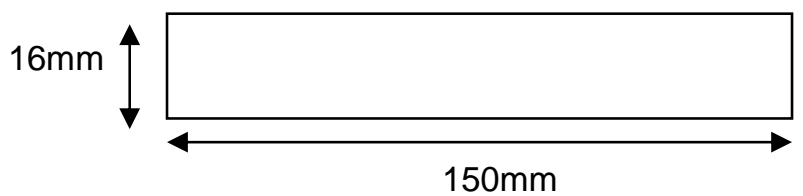

Fig 1: $150 \mathrm{~mm}$ mild steel rod
Welding of the specimen: Each specimen was finely ground and welded by an Electric arc welding machine to another specimen at its end of same length. It was cooled by different coolant (air, water, coconut oil, palm oil, groundnut oil). The cooling rate of the specimens at different coolants was taken and recorded at a 3minute interval. After cooling, the cool unaffected zone is then cut out and the specimens was then weighed on a sensitive weighing balance and placed in a desiccating region, to prevent moisture from touching it and to prevent corrosion prior to further experimentation.

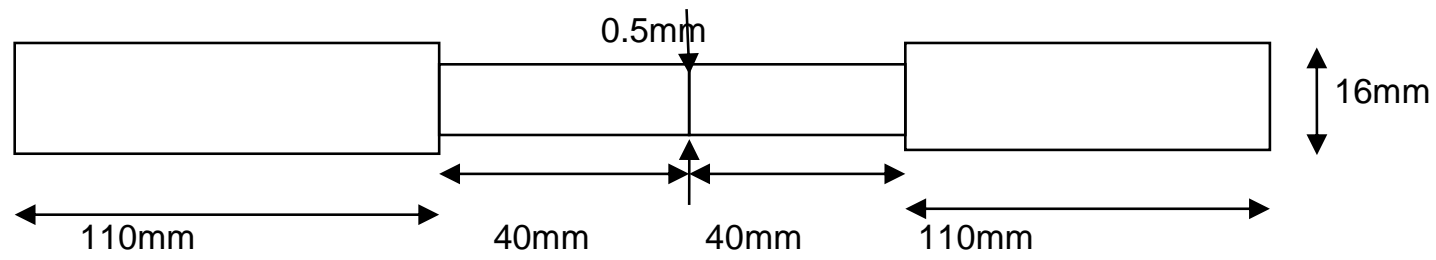

Fig 2: Welding specimen.

Corroding media preparation: The corrosive media such as cassava water which is also called hydrogen cyanide fluid was extracted from freshly harvested cassava tuber after peeling and grinding, from a local cassava- processing industry at $\mathrm{Aba}$ - Igbira, Adebayo, along Iworoko road, Ado Ekiti. Table water was gotten and procured from nearby environment in equal volume of $75 \mathrm{cl}$. The initial weight of the prepared and locally welded and cooled specimen was taken before immersed completely into its corrosive media (water and cassava water) maintained at room temperature.

Experimentation: After cooling of specimen was performed (first two specimen was cooled by palm oil, then another two by water, then another two by groundnut oil, another two specimens was cooled by coconut oil and last two specimens was cooled by air), then placing the specimens each in a corrosive media (one specimen cooled by water, air, palm oil, ground nut oil, coconut oil is placed in each corrosive medium) prior to that the initial weights has been taken and hence complete immersion of the specimen in its corrosive solutions. Weighing was done every 120hours for 720hours. At every 120 hours interval, the specimens was removed from the solution and descaled with an emery paper and cleaned and then returned back to its solution, after the weight loss has been taken. Specimens from the cassava water were washed thoroughly under running tap and dried, then reweighed. This helped to remove all deposits from the rod and allow freshly new surface for corrosion. Each specimen was subsequently weighed on a sensitive weighing balance to determine its weight loss. The corrosion rate given was used to determine its corrosion rate using the formula written by (Krishner, 2011).

$$
\mathrm{CR}(\mathrm{mm} / \mathrm{yr} .)=\frac{876 \mathrm{w}}{p \mathrm{At}} \quad \ldots \ldots . .(\text { Equation } 1)
$$

$\mathrm{CR}$ is corrosion rate in $\mathrm{mm} / \mathrm{yr}$.

$\mathrm{w}$ is weight loss, $\mathrm{g}$

$p$ is density of specimen $\mathrm{g} / \mathrm{cm}^{3}$

$A$ is total surface area, $\mathrm{cm}^{2}$

$\mathrm{t}$ is time of immersion in corrosive medium, $\mathrm{hr}$.

\section{RESULTS AND DISCUSSION}

The effect of local coolants used (palm oil, ground nut oil, water, air and coconut oil) in the different welded mild steel rods which were immersed in two corrosive media (water and cassava water) has been studied

Table 1 showed the results of the actual weight loss of specimens immersed in table water. Weight loss of 
Am. J. Sci. Ind. Res., 2013, 4(1): 153-160

specimen cooled by water was the highest $(3.50 \mathrm{~g})$, followed by groundnut oil $(3.00 \mathrm{~g})$, then coconut oil, palm oil and specimen cooled by air $(1.00 \mathrm{~g})$. However, the graphical representations of these variations are shown below in figure 4 as the graph of weight loss was plotted against exposure time immersed in its corrosive media.
Table 2 showed the corrosion rates in table water and figure 5 showed the corrosive rates against time in table water. Corrosion rate of specimen cooled by water had the highest corrosive rate of $1.08 \mathrm{~mm} / \mathrm{yr}$, followed by groundnut oil at $0.92 \mathrm{~mm} / \mathrm{yr}$ till the last one specimen cooled by air was least in table water at

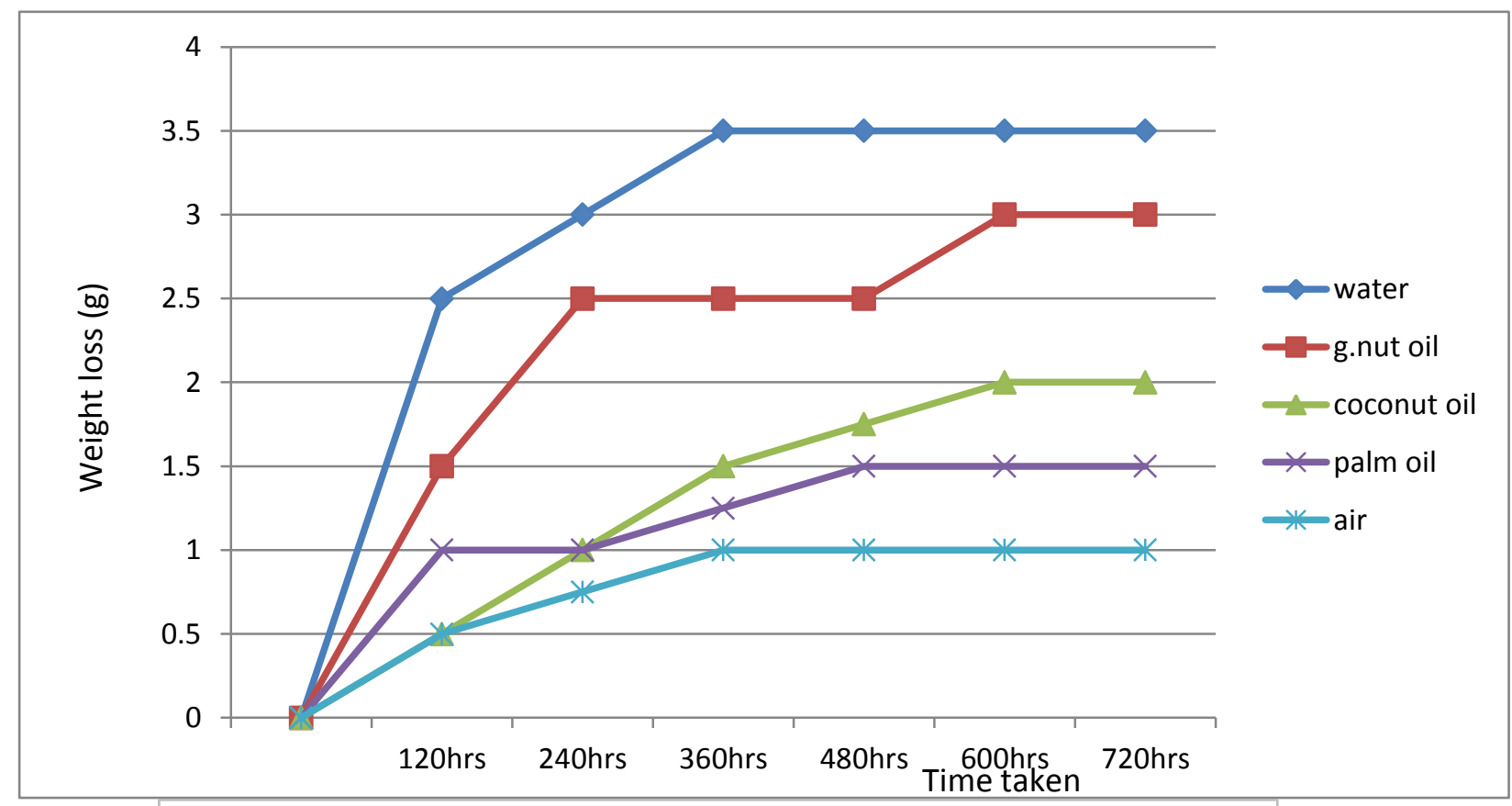

Fig 3: Variations of weight loss of specimens immersed in table water 
Am. J. Sci. Ind. Res., 2013, 4(1): 153-160

Table 1: Weight loss of specimens immersed in table water in respect with time

\begin{tabular}{|c|c|c|c|c|c|c|c|}
\hline \multirow{2}{*}{$\begin{array}{c}\text { Coolants } \\
\text { used/Time taken }\end{array}$} & \multicolumn{7}{|c|}{ Weight loss(g) } \\
\cline { 2 - 8 } & Ohours & 120 hours & 1240 hours & 360 hours & 480hours & 600 hours & 720 hours \\
\hline Water & 0 & 2.50 & 3.00 & 3.50 & 3.50 & 3.50 & 3.50 \\
\hline Ground nut oil & 0 & 1.50 & 2.50 & 2.50 & 2.50 & 3.00 & 3.00 \\
\hline Coconut oil & 0 & 0.50 & 1.00 & 1.50 & 1.75 & 2.00 & 2.00 \\
\hline Palm oil & 0 & 1.00 & 1.00 & 1.25 & 1.50 & 1.50 & 1.50 \\
\hline Air & 0 & 0.50 & 0.75 & 1.00 & 1.00 & 1.00 & 1.00 \\
\hline
\end{tabular}

Table 2: Corrosion rates of specimens immersed in table water in respect with time

\begin{tabular}{|c|c|c|c|c|c|c|}
\hline \multirow[t]{2}{*}{ Coolants/Time taken } & \multicolumn{5}{|c|}{ Corrosion rates(mm/yr) } & \multirow[b]{2}{*}{ 720hours } \\
\hline & 120hours & 240hours & 360hours & 480hours & 600hours & \\
\hline Water & 4.62 & 2.77 & 2.15 & 1.62 & 1.29 & 1.08 \\
\hline Ground nut oil & 2.77 & 2.31 & 1.54 & 1.15 & 1.11 & 0.92 \\
\hline Coconut oil & 0.92 & 0.92 & 0.92 & 0.81 & 0.74 & 0.62 \\
\hline Palm oil & 1.85 & 0.92 & 0.77 & 0.69 & 0.55 & 0.46 \\
\hline Air & 0.92 & 0.69 & 0.62 & 0.46 & 0.37 & 0.31 \\
\hline
\end{tabular}

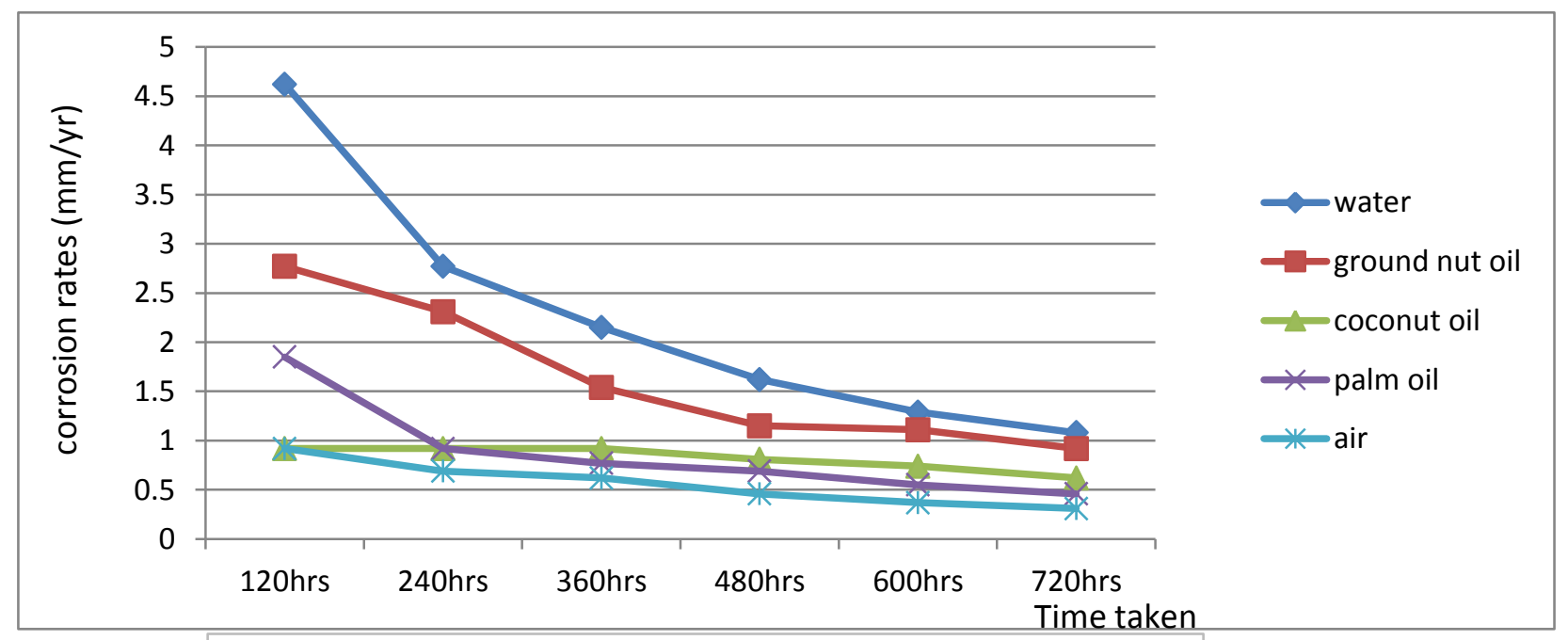

Fig 4: Corrosion rates of specimens immersed in table water

Table 3: Weight loss of specimens immersed in cassava water in respect with time taken

\begin{tabular}{|l|c|c|c|c|c|c|c|}
\hline Coolants/Time taken & \multicolumn{7}{|c|}{ Weight loss(g) } \\
\cline { 2 - 8 } & 0 & 12 hours & 240 hours & 360 hours & 480 hours & 600 hours & 720 hours \\
\hline Water & 0 & 2.50 & 4.50 & 5.00 & 5.50 & 6.50 & 6.50 \\
\hline Groundnut oil & 0 & 1.00 & 2.50 & 3.00 & 3.50 & 4.00 & 4.00 \\
\hline Coconut oil & 0 & 1.00 & 1.00 & 1.50 & 2.00 & 2.50 & 2.50 \\
\hline Palm oil & 0 & 1.00 & 1.50 & 1.50 & 2.00 & 2.00 & 2.00 \\
\hline Air & 0 & 0.50 & 1.00 & 1.25 & 1.50 & 1.50 & 1.50 \\
\hline
\end{tabular}


Table 3 gives the weight difference of the specimens immersed in cassava water. Specimen cooled by water has the highest weight loss of $6.50 \mathrm{~g}$, then specimen cooled by ground nut oil $(4.00 \mathrm{~g})$ followed by specimen cooled by coconut oil $(2.50 \mathrm{~g})$ then specimen cooled by palm oil to be $2.00 \mathrm{~g}$ with air cooled specimen having the least weight loss of $1.50 \mathrm{~g}$. Figure 6 gave a variation of the specimens plotted by weight loss against time, gotten from table 3.

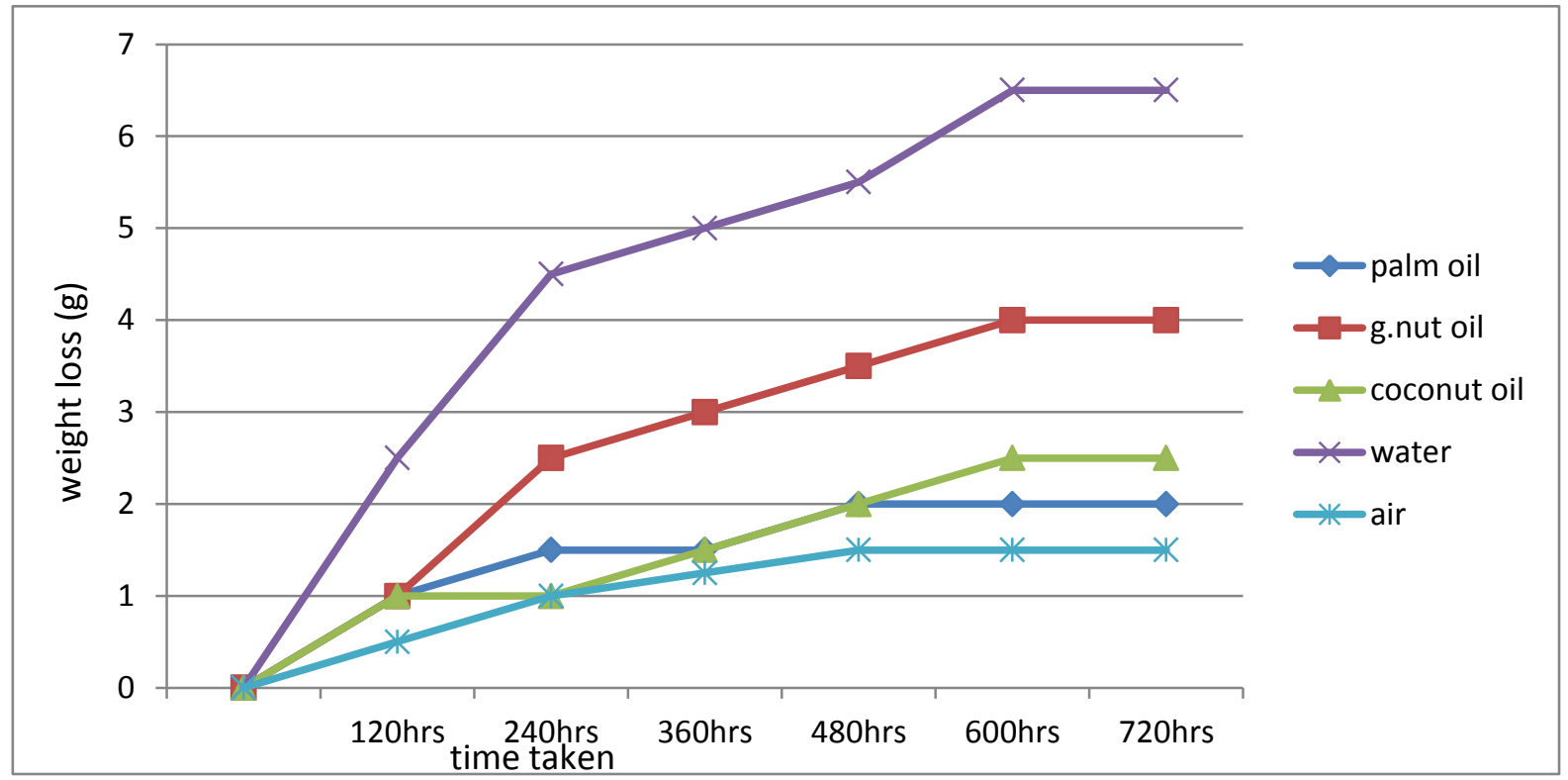

Fig 5: Variation of weight loss of specimens immersed in cassava water

Table 4: Corrosion rates of Specimens immersed in Cassava water in respect with Time

\begin{tabular}{|l|c|c|c|c|c|c|}
\hline \multirow{2}{*}{ Coolants } & \multicolumn{6}{|c|}{ Corrosion rates(mm/yr) } \\
\cline { 2 - 7 } & 12 hours & 240 hours & 36 hours & 480 hours & 600 hours & 720 hours \\
\hline Water & 4.629 & 4.15 & 3.07 & 2.54 & 2.39 & 2.00 \\
\hline Groundnut oil & 3.69 & 2.31 & 1.85 & 1.62 & 1.48 & 1.07 \\
\hline Coconut oil & 1.85 & 0.92 & 0.92 & 0.92 & 0.92 & 0.76 \\
\hline Palm oil & 1.85 & 1.38 & 0.92 & 0.92 & 0.74 & 0.62 \\
\hline Air & 0.92 & 0.92 & 0.77 & 0.69 & 0.55 & 0.46 \\
\hline
\end{tabular}

From table 4 , specimen cooled by water was most corroded in this cassava water at $2.00 \mathrm{~mm} / \mathrm{yr}$ followed by specimen cooled by groundnut oil at $1.07 \mathrm{~mm} / \mathrm{yr}$ then specimen cooled by palm oil at $0.62 \mathrm{~mm} / \mathrm{y}$, air cooled was least corroded specimen at $0.46 \mathrm{~mm} / \mathrm{yr}$, with its respective figure 7 , showing its graphical representation of corrosion rate of specimen immersed in cassava water. 
Am. J. Sci. Ind. Res., 2013, 4(1): 153-160

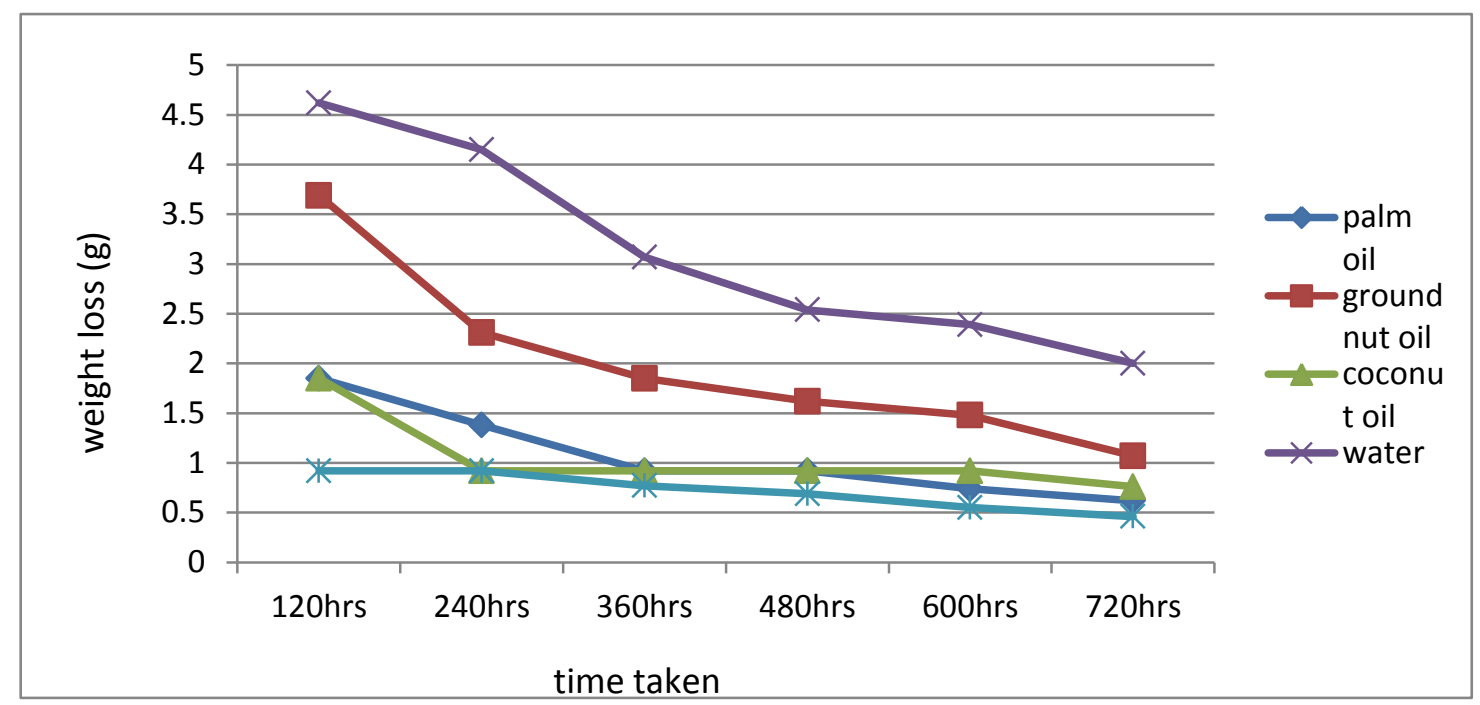

Fig 6 : Corrosion rates of specimens immersed in cassava water

\section{CONCLUSION}

This project work has been able to evaluate the trend of corrosion rates of mild steel weldments in water storage and transport facilities and gari (food) processing equipments. These are experimentally simulated by using table water and cassava water respectively as the corrosive media. Though weight loss increases with increase in immersion time, corrosion rate does not follow the same trend due to stagnant ions blocking the creation of more ions and thus reducing $\mathrm{Fe}^{2+}$ activities in the solution. The findings of this research work showed that waterquenched weldments (specimen cooled by water) have the fastest rate of corrosion in all the corrosive media; while air quenched weldments displayed the least corrosion rates. Hence, water- quenching in industries is not recommended. Also, air cooling of weldments cause downtime in production; hence, air cooling is also not recommended.

Groundnut oil- quenched weldments is not recommended for the usage in water storage/transport and gari processing facilities (water and cassava water) because of the relatively higher corrosion rate it displayed in the respective media.Palm oil- quenched weldments is recommended for usage in water storage/transport and gari processing facilities because of its relatively low corrosion rates. Coconut oil- quenched weldments is not recommended for any usage at all because it has relatively higher corrosion rates.

\section{REFERENCES}

Ashby, Michael F.; David R. H. Jones (1992).

Engineering Materials 2 (with 4th ed.). Oxford: Pergamon Press. ISBN 0-08-032532-7.

Smith, William F.; Hashemi, Javad (2006) Foundations of Materials Science and Engineering (4th ed.), McGrawHill, ISBN 0-07-295358-6. pp 373-378.

Baroux, B (1995); Corrosion mechanism in theory and practices, Marcel Dekker press.

Callister, W.D., (1992) Materials science and Engineering, 4th ed. John Wiley, New York.

Kendrim, O. C., Chukwu, O A., Achinewhu, S. C., Effect of Traditional Processing of Gari and Cassava Flour, Plant Food for Human Nutrition, 48, 335-339, 1995.

Holleman, A. F., Wiberg E. (2001) "Inorganic Chemistry" Academic press, San Diego. ISBN 0-12-352651-5.

Weman, k. (2008), Welding processes handbook, New York. CRC press LLC ISBN 0-0493-1773-8.

Ita B.I, Offiong O.E (1999). "Adsorption studies on the corrosion inhibition properties of 2-acetylpyrole and 2acetylpyrole-(2- acetylthiosemicarbazone) on mild steel in hydrochloride acid medium". Global J. Pure and App. Sci. 5(4): pp 497-501 
Am. J. Sci. Ind. Res., 2013, 4(1): 153-160

G.A Zhang, Y.W Cheng (2009): micro-electrochemical characterization and Mott- Schottky analysts of corrosion of welded X70 pipeline steel in carbonate/bicarbonate solution. Electrochimica Acta 55(1), pp 316-324.

Farina C.A, Faita G, Olivani F(2004): “Electrochemical Behaviour of metals in $\mathrm{HNO} 3$ solution" Chemical science index, 23:906-910.

Gawrilow, I.L (2003) "palm oil usage in lubricants". Third Global oils and fats business forum USA.
Alagbe, M., L.E Umoru, A.A Afonja (2005) "Investigation on the inhibition of NST- 44 mild steel corrosion in cassava fluid". Botswana J. Tech. (in review).

Jekayinfa, S. O., Waheed, M. A., Adebiyi K. A., and Adebiyi, F. T., (2005) The effect of cassava fluid on the corrosion performance of mild steel, Anti- corrosion methods and materials, emerald group publishing Itd. vol. 52, Issue 5, pp. 286-292.

Krishner, A.S., Technical Information Regarding Coupon Testing in Metal Samples Corrosion Monitoring Systems, retrieved from www.aispi.com/cpntst.htm 